\title{
Educação financeira como estratégia na Formação Integral dos estudantes da Educação Profissional e Tecnológica
}

\section{Financial education as a strategy in the Integral Formation of students of Professional and Technological Education}

Recebido: 30/04/2020 | Revisado:

15/09/2020 | Aceito: 26/10/2021 |

Publicado: 17/02/2021

Marina Gonçalves

ORCID: https://orcid.org/0000-0003-11103104

Instituto Federal de Educação, Ciência e

Tecnologia do Sul de Minas

E-mail:

marina.goncalves@ifsuldeminas.edu.br

Rafael Felipe Coelho Neves

ORCID: https://orcid.org/0000-0003-3819-

1714

Instituto Federal de Educação, Ciência e

Tecnologia do Sul de Minas

E-mail: rafael.neves@ifsuldeminas.edu.br

Como citar:

GONÇALVES, M; NEVES, R. F. C.; Educação financeira como estratégia na Formação Integral dos estudantes da Educação Profissional e Tecnológica Revista Brasileira da Educação

Profissional e Tecnológica, [S.I.], v. 1, n. 20, p. e10019, fev. 2021. ISSN 2447-1801. Disponível em: <http://www2.ifrn.edu.br >

This work is licensed under a Creative Commons Attribution 4.0 Unported License.

\begin{abstract}
Resumo
O presente artigo é uma contribuição para que o ensino de Educação Financeira possa ser difundido e estimulado. Por meio de um produto educacional e com ênfase no consumo consciente do dinheiro e do crédito, esse trabalho objetivou registrar a percepção dos estudantes e do professor sobre a introdução do tema na Educação Profissional e Tecnológica. A coleta de dados se efetivou por meio de aplicação de questionários e ocorreu em três etapas. A aplicação do produto educacional, no formato de cartilha, foi realizada pelo professor, por meio de aula expositiva e com utilização de exemplos práticos do cotidiano. Este trabalho, além de facilitar a compreensão de conceitos, também fornece informações e condições para que estudantes e professor transformem os conhecimentos em comportamentos financeiros saudáveis.
\end{abstract}

Palavras-chave: Ensino; Educação Financeira; Formação integral; Educação Profissional e Tecnológica.

\section{Abstract}

This article is a contribution so that the teaching of Financial Education can be disseminated and stimulated. Through an educational product and with an emphasis on the conscious consumption of money and credit, this work aimed to record the perception of students and the teacher about the introduction of the theme in Professional and Technological Education. Data collection was carried out through the application of questionnaires and occurred in three stages. The application of the educational product, in the format of a booklet, was carried out by the teacher, through an expository class and using practical examples from everyday life. This proposal, in addition to facilitating the understanding of concepts, also provides information and conditions for students and teachers to transform knowledge into healthy financial behaviors.

Keywords: Teaching; Financial Education; Integral Education; Professional and Technological Education. 


\section{INTRODUÇÃO}

No Brasil, o cenário econômico tem sido marcado pelo crescente grau de endividamento das famílias, gerando preocupação tanto para a população quanto para o governo. A expansão elevada do crédito, resultado de uma relativa estabilidade econômica e inflação baixa, atinge parcelas da população que não têm condição de atuar de uma forma mais estruturada diante do desafio de não se endividar ou até mesmo de solicitar crédito de forma consciente. Brasileiros passaram a utilizar de forma indiscriminada os inúmeros tipos de créditos disponíveis no mercado, dentre eles os mais comuns estão: financiamento de casa, de veículo e uso de cartão de crédito.

Como agravamento da situação, observa-se uma sociedade com alta exposição às propagandas e apelo para o consumo. Ferreira (2008) aponta que a cada dia são lançados novos produtos, muitas vezes com pequenas alterações em relação aos modelos anteriores, tão somente para estimular sua substituição. Com esse grande impacto no comportamento em relação ao consumo, o cidadão com a renda já comprometida, se vê obrigado a fazer escolha entre pagar as dívidas ou manter as despesas fundamentais para a sobrevivência. Nesse sentido, o autor relaciona, o consumismo exacerbado à desigualdade social e à falta de Educação Financeira, o que leva muitas famílias ao endividamento e consequentemente, à privação de bens de consumo essenciais a uma vida digna.

Como resultado, pode-se citar o aumento do percentual de famílias com dívidas em dezembro de 2019, alcançando $65,6 \%$ e chegando ao maior patamar da série histórica da Pesquisa de Endividamento e Inadimplência do Consumidor (PEIC), realizada pela Confederação Nacional do Comércio de Bens, Serviços e Turismo (CNC) desde janeiro de 2010. Diante dessa realidade, é evidente a importância da disseminação do ensino de Educação Financeira à população, voltada para o planejamento dos gastos e consumo consciente do crédito disponível. Inserir essa temática na educação formal, sobretudo na Educação Profissional e Tecnológica (EPT) pode ser uma maneira eficiente de valorizar o trabalho como produtor de riqueza para a sociedade e de bem-estar pessoal e social.

Assim, com o propósito de colaborar para o desenvolvimento da EPT, com foco nas estratégias transversais e interdisciplinares, que possibilitem a formação significativa dos estudantes, este trabalho objetivou registrar a percepção dos estudantes e dos professores sobre a introdução da Educação Financeira na EPT por meio de um produto educacional no formato de cartilha, como uma estratégia para contribuir para a formação integral, e consequentemente, com o fortalecimento da cidadania dos estudantes dos cursos técnicos subsequentes.

No formato de cartilha e destinado aos professores, o produto disponibiliza conteúdos básicos sobre finanças pessoais, com ênfase no consumo consciente do dinheiro e do crédito. Em acréscimo, foi desenvolvido um website para disseminação do conhecimento e acesso irrestrito da cartilha pelos estudantes que pode ser acessado através do endereço edufinanceiraept.com. 


\section{EDUCAÇÃO FINANCEIRA E A ESTRATÉGIA BRASILEIRA}

O poder de consumo da população brasileira foi ampliado nas últimas décadas, graças à estabilidade econômica obtida pela redução da inflação. Esse ambiente econômico estável proporcionou um aumento na oferta de produtos financeiros ao consumidor, ou seja, possibilitou maior consumo de bens de necessidade básica e bens duráveis.

Segundo o Bacen (2013), para usufruir dos benefícios oferecidos pelos diversos produtos disponíveis no mercado, principalmente do crédito, são necessários alguns conhecimentos e comportamentos básicos, dentre eles: consumir de forma consciente, evitando o consumismo compulsivo; saber se comportar diante das oportunidades de financiamentos disponíveis, utilizando o crédito com sabedoria e evitando o superendividamento; entender a importância e as vantagens de planejar e acompanhar o orçamento pessoal e familiar; compreender que o ato de poupar e investir são um bom caminho, tanto para concretizar sonhos, realizando projetos, como para reduzir os riscos em eventos inesperados; e, por fim, manter uma boa gestão financeira pessoal.

Esses comportamentos básicos são promovidos por intermédio da Educação Financeira. "Aqui entra a escola, com o intuito claro de ajudar na construção da autonomia do aluno e fornecer-Ihes ferramentas para ser tanto mais autônomo quanto mais informado." (STEPHANI, 2005, p. 11)

Kern (2009) ainda reforça que a inclusão da Educação Financeira na escola, relacionando conteúdos curriculares com situações do cotidiano, pode ser uma alternativa na busca de uma aprendizagem significativa do estudante. Nesse sentido, este artigo assume a estratégia de abordar as potencialidades e possibilidades da inserção da Educação Financeira na EPT, partindo do pressuposto de uma Educação Financeira como prática social, oposta às propostas que são intencionadas a suprir necessidades do mercado, do capital financeiro. Afinal, segundo Moura (2013), é possível e necessário, plantar e cuidar para que cresçam as sementes da formação humana integral, aproveitando-se das contradições do sistema de capital.

De acordo com a conceituação da Organização para Cooperação e Desenvolvimento Econômico (OCDE), Educação Financeira é o processo mediante o qual os indivíduos e as sociedades melhoram a sua compreensão em relação aos conceitos e produtos financeiros, de maneira que com informação, formação e orientação possam desenvolver as competências e os valores necessários para se tornarem mais conscientes das oportunidades e riscos neles envolvidos e, então, poderem fazer escolhas bem informadas, saber onde procurar ajuda, adotar outras ações que melhorem o seu bem-estar e, assim, tenham a possibilidade de contribuir de modo mais consistente para a formação de indivíduos e sociedades responsáveis, comprometidos com o futuro.

Ou seja, com a Educação Financeira, o cidadão poderá fazer escolhas baseadas em informação, saber onde procurar ajuda e adotar diferentes ações efetivas que melhorem o seu bem-estar. Conforme esclarece Domingos (2016), ao contrário do que muitas pessoas pensam, Educação Financeira não se trata de cálculos matemáticos, planilhas e fórmulas, mas sim de uma metodologia que 
promove a mudança de comportamento e hábitos errôneos - arraigados ao longo de décadas - em relação ao uso e à administração do dinheiro. Contribuindo para o entendimento, Hill (2009) denomina Educação Financeira como a habilidade que os indivíduos apresentam de fazer escolhas adequadas ao administrar suas finanças pessoais durante o ciclo de sua vida.

A Educação Financeira tornou-se uma preocupação crescente em diversos países. Segundo a Associação de Educação Financeira do Brasil, AEF Brasil (2017), as implicações sociais e econômicas, a longo prazo do baixo índice de Educação Financeira de grande parte da população mundial, têm levado os governos a criar políticas específicas especialmente a partir de 2008. Inclusive, fóruns globais e regionais como o G20 e a Cooperação Econômica Ásia-Pacifico (APEC) já reconheceram a importância dos esforços nacionais de educação financeira para sustentar a estabilidade econômico-financeira e o desenvolvimento social inclusivo. Com efeito, no âmbito dos países do G20, as estratégias nacionais de educação financeira têm-se proliferado. Cerca de metade deles já desenvolveram uma estratégia: Austrália, Brasil, Japão, Holanda, África do Sul, Espanha, Reino Unido e Estados Unidos.

Aliás, no Brasil o tema ganhou relevância nos últimos anos, principalmente por conta da crescente expansão do crédito ao consumidor, inclusive ao cidadão de baixa renda, que anteriormente não possuía acesso aos produtos do mercado financeiro. Foi essa necessidade de educar o cidadão financeiramente determinou a instituição da Estratégia Nacional de Educação Financeira (ENEF), instituída como política de Estado de caráter permanente, por meio do Decreto Presidencial no 7.397/2010, que tem como finalidade: fortalecer a cidadania, aumentar a eficiência e solidez do sistema financeiro, disseminar a Educação Financeira e previdenciária e promover a tomada de decisões financeiras conscientes e autônomas.

Juntamente com a ENEF, foi criado o Comitê Nacional de Educação Financeira (CONEF), por meio da articulação de nove órgãos e entidades governamentais e quatro organizações da sociedade civil, que recebeu a responsabilidade de definir planos, programas, ações e coordenar a execução da ENEF. Dentre as diretrizes da ENEF, pode-se destacar: atuar com informação, orientação e formação; gratuidade das ações e prevalência do interesse público; e gestão centralizada, atividades descentralizadas. Seu foco está no desenvolvimento de programas transversais para três públicos-alvo: crianças, jovens e adultos. Dentre esses programas transversais, que estão sob a coordenação da AEF-Brasil, pode-se citar:

- Programa Educação Financeira nas Escolas: propõe levar a Educação Financeira para o ambiente escolar;

- Programa Educação Financeira de Adultos: inicialmente com públicosalvo mulheres beneficiárias do Programa Bolsa Família e aposentados com renda de até dois salários mínimos;

- Semana Nacional de Educação Financeira: uma ação de mobilização que objetiva disseminar o tema para todo o país.

Com o objetivo de introduzir a Educação Financeira em todo o processo de formação dos jovens, a ENEF desenvolveu o Programa Educação Financeira nas 
Escolas, levando esse conhecimento para a educação básica. A Educação Financeira, entendida como tema transversal, dialoga com as diversas disciplinas dos currículos do ensino fundamental e médio, de forma a possibilitar ao estudante compreender como concretizar suas aspirações e estar preparado para as diversas fases da vida.

Segundo a AEF-Brasil (2017), quando se trabalha a Educação Financeira no ambiente escolar contribui-se com a construção das competências necessárias para que os estudantes enfrentem os desafios sociais e econômicos da sociedade e para o exercício da cidadania. Ou seja, a escola é o ambiente em que os estudantes adquirem não apenas conhecimentos, como também a capacidade de viver em sociedade, fazendo escolhas que influenciarão na realização dos seus sonhos e suas atitudes influenciam na sociedade.

Recentemente, se "celebrou mais um avanço: a homologação da Base Nacional Comum Curricular (BNCC) e a inclusão da Educação Financeira entre os temas transversais que devem entrar nos currículos das escolas brasileiras nos próximos anos." (AEF-BRASIL, 2017). Nesse sentido, o parecer do Conselho Nacional de Educação, homologado pelo Ministério da Educação, prevê que as redes de ensino adaptem os currículos da educação infantil e fundamental, incluindo esta competência no ensino, até este ano, 2020.

No mais, a Educação Financeira se mostra não apenas um grande diferencial para as escolas, mas também uma necessidade para toda a população. E se trabalhada como tema transversal no ambiente escolar, pode contribuir para 0 desenvolvimento de valores, conhecimentos e competências importantes na condução de uma vida financeira autônoma dos estudantes. "Quanto mais próximo da vida o aluno aprender, melhor. Isso vai ao encontro da educação libertadora, defendida por Paulo Freire." (FONSECA; NETO, 2017, p. 188).

\section{METODOLOGIA}

O presente trabalho teve como finalidade atingir o objetivo proposto por meio de uma pesquisa exploratória, com abordagem qualitativa e, possivelmente, com utilização de algumas técnicas de mensuração de dados. A coleta de dados foi realizada por meio de aplicação de questionários.

O estudo teve como população alvo a turma de estudantes do curso Técnico em Administração na forma subsequente do Instituto Federal de Educação, Ciência e Tecnologia do Sul de Minas Gerais - IFSULDEMINAS - , Campus Poços de Caldas. Assim, o estudo teve uma amostra composta por 20 alunos, sendo 13 do sexo feminino e 7 do sexo masculino, com faixa etária compreendida entre 17 e 29 anos. Quanto ao estado civil, 95\% dos integrantes se declararam solteiros e apenas 5\% casados.

Os questionários, compostos por questões fechadas, dicotômicas e de múltipla escolha, foram aplicados em três etapas. A primeira, anterior ao desenvolvimento do produto educacional, ocorrida no mês de outubro de 2019, contou com 26 questões que se destinaram a uma investigação do perfil e dos hábitos 
financeiros dos alunos; a segunda, ocorrida logo em seguida da aplicação do produto, foi composta por 11 questões e visou avaliar o impacto do conteúdo transmitido aos estudantes, tendo em vista sua contribuição para a formação integral, e consequentemente, o fortalecimento da cidadania; $\mathrm{E}$ a terceira e última etapa, realizada também após a aplicação do produto, foi composta de 16 questões e destinada ao professor que fez a avaliação do produto educacional proposto.Vale ressaltar que para o desenvolvimento dos questionários, além das questões de autoria da pesquisadora, também foram selecionadas algumas questões de AEF-Brasil (2019), Bacen (2013), CONEF (2013), Leite (2018) e Kaplún (2003), inclusive algumas foram ajustadas para o contexto da pesquisa.

Concluída a primeira etapa de aplicação dos questionários, estudos sobre a temática "Educação Financeira" foram realizados, buscando identificar na literatura conceitos básicos reconhecidos pela ENEF que contribuíssem para o conhecimento significativo dos estudantes. A fim de facilitar e estimular a introdução do tema na EPT, posteriormente, foi desenvolvido o produto educacional, no formato de cartilha, destinado aos docentes (este produto pode ser encontrado em edufinanceiraept.com). Afinal, no momento em que os professores se percebem como agentes de promoção da Educação Financeira o tema é disseminado nas salas de aula. O conteúdo desta $1^{\text {a }}$ Edição da cartilha teve foco no consumo consciente do dinheiro e do crédito e foi organizado em tópicos, alinhado com os objetivos, competências e conceitos relacionados à ENEF.

A aplicação do produto educacional foi feita pelo professor responsável pela disciplina de Comportamento Humano nas Organizações e ocorreu no mês de dezembro de 2019 no formato de aula expositiva e com utilização de exemplos práticos do cotidiano. Finalmente com o desenvolvimento e aplicação do produto educacional e efetivada as três etapas de aplicação dos questionários, foi possível a realização da análise e interpretação dos dados coletados, e o tratamento dos resultados.

\section{RESULTADOS E DISCUSSÕES}

O estudo teve como população alvo a turma de estudantes do curso Técnico em Administração na forma subsequente do IFSULDEMINAS, Campus Poços de Caldas, composta por 20 alunos. Esta primeira etapa da coleta de dados, ocorrida no mês de outubro de 2019, objetivou investigar o perfil da amostra e seus respectivos hábitos financeiros. Em relação ao perfil da amostra, foram 13 do sexo feminino e 7 do sexo masculino, com faixa etária compreendida entre 17 e 29 anos. Quanto ao estado civil, $95 \%$ dos integrantes se declararam solteiros e apenas $5 \%$ casados.

Sobre a atual situação financeira, $50 \%$ dos estudantes se sentem preocupados porque o dinheiro não sobra. Nesse sentido a Educação Financeira é importante para auxiliar os jovens a planejar e gerir sua renda, poupar, investir e garantir uma vida financeira mais tranquila. Mas, infelizmente, o tema ainda não é um conteúdo comum dos currículos escolares e, como consequência disso, metade dos estudantes afirmaram que a aula expositiva, fruto da aplicação da cartilha, foi o primeiro contato com o tema Educação Financeira. 
Como já visto anteriormente, o primeiro passo para o controle do dinheiro é a prática de se fazer um orçamento, que em linhas gerais é uma forma de planejamento financeiro. Sobre o orçamento, $30 \%$ dos participantes afirmaram que fazem uma tabela com o que ganha e gasta para ter mais controle sobre a vida financeira. Metade da turma afirmou que já fez um orçamento para reduzir gastos em um mês que queria economizar. Nesse ponto, vale ressaltar que reduzir gastos é uma das funções do orçamento, mas não é a única. Um orçamento é um instrumento para que você possa ter maior controle sobre sua vida financeira e, a partir daí, planejar para alcançar suas metas.

Ainda sobre o planejamento, como uma das consequências da não elaboração, $40 \%$ da turma afirmaram que, às vezes, não consegue pagar algumas contas. A questão que pergunta sobre o costume de listar todos os gastos mensais foi duplicada destinando-se também aos pais e/ou responsáveis. Pode-se afirmar que houve um retorno discrepante entre pais e filhos. Enquanto apenas $5 \%$ da turma admitiram nunca ter feito uma lista com todos os gastos mensais; quando perguntado da realidade dos pais e/ou responsáveis, 65\% confessaram que os pais nunca fizeram. Essa situação foi elucidada quando perguntados sobre a relação com a família, onde $35 \%$ dos estudantes declararam não conversar sobre questões financeiras com seus familiares e $25 \%$ da turma afirmaram que só comentam quando a família pede ajuda.

Em relação à decisão de compra de um novo bem, metade prefere poupar para comprar à vista e a outra metade compra imediatamente utilizando alguma das diversas formas de créditos disponíveis no mercado. Sobre as dificuldades para realização de um planejamento financeiro, é possível a certificação dos itens, logo abaixo, no Gráfico 1.

Gráfico 1: Itens que dificultam o planejamento financeiro

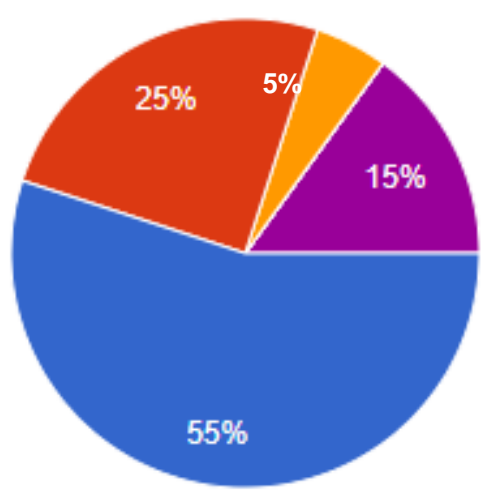

Busca pelo prazer imediato.

Pouca formação financeira.

Comprometimento da tomada de decisão por fatores como publicidade ou opinião de amigos e familiares

Memória inflacionária.

Todas as anteriores.

Fonte: Elaborado pela autora

Conforme o Gráfico 1, quando indagados sobre os itens que dificultam o planejamento financeiro, $55 \%$ dos jovens confessaram a busca pelo prazer imediato e $25 \%$ declararam a pouca formação financeira. 
Um erro muito comum no controle das despesas é as pessoas se esquecerem de anotar as despesas de pequeno valor. Esses gastos pequenos se acumulam durante o mês e podem se tornar gastos de grande vulto. Nesse quesito, $80 \%$ dos estudantes focam somente nos gastos maiores. Por falar em gastos de grande vulto, no Gráfico 2, é possível verificar as despesas que mais comprometem a renda dos estudantes.

Gráfico 2: Comprometimento da renda por tipo de despesa

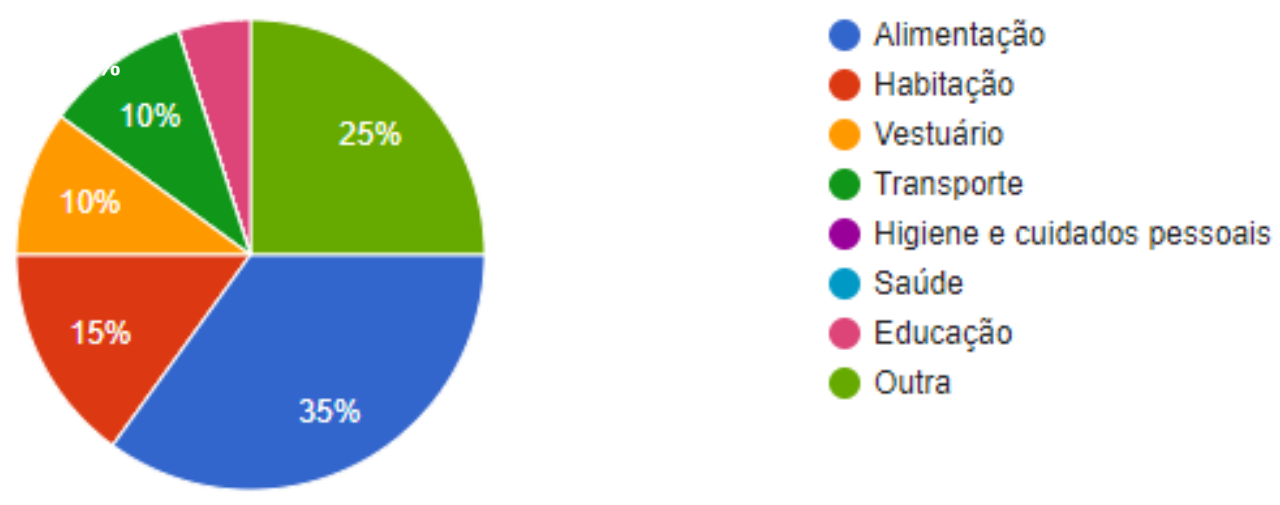

Fonte: Elaborado pela autora

Como demonstrado no Gráfico 2, 35\% dos estudantes declararam a alimentação como o item que mais compromete sua renda e as despesas com habitação comprometem a renda de $15 \%$ da turma. Vale lembrar que $95 \%$ da amostra se declararam solteiros, e há grandes possibilidades de ainda estarem morando com os pais; tal fato poderia justificar a alimentação superar a habitação no quesito de comprometimento de renda.

Outro aspecto importante, segundo o Bacen (2013), é ao fazer escolhas, saber distinguir desejo de necessidade. Pode-se definir necessidade como tudo aquilo de que precisamos independentemente de nossos anseios. São coisas absolutamente indispensáveis para nossa vida. Por sua vez, os desejos podem ser definidos como tudo aquilo que queremos possuir ou usufruir, sendo essas coisas necessárias ou não. Nessa acepção, quando questionado se analisam a real necessidade da compra quando decidem comprar algo, 65\% dos estudantes afirmaram que já compraram por impulso ou ainda compram e depois se arrependem. Ademais, os "recursos devem satisfazer as necessidades, mas, na medida do possível, podem-se atender os desejos." (BACEN, 2013) Ao tratar os desejos como se fossem necessidades surge o problema, pois os desejos são ilimitados, porém os recursos são limitados. do Gráfico 3.

Quanto à destinação do excedente do mês, é possível a apuração por meio 


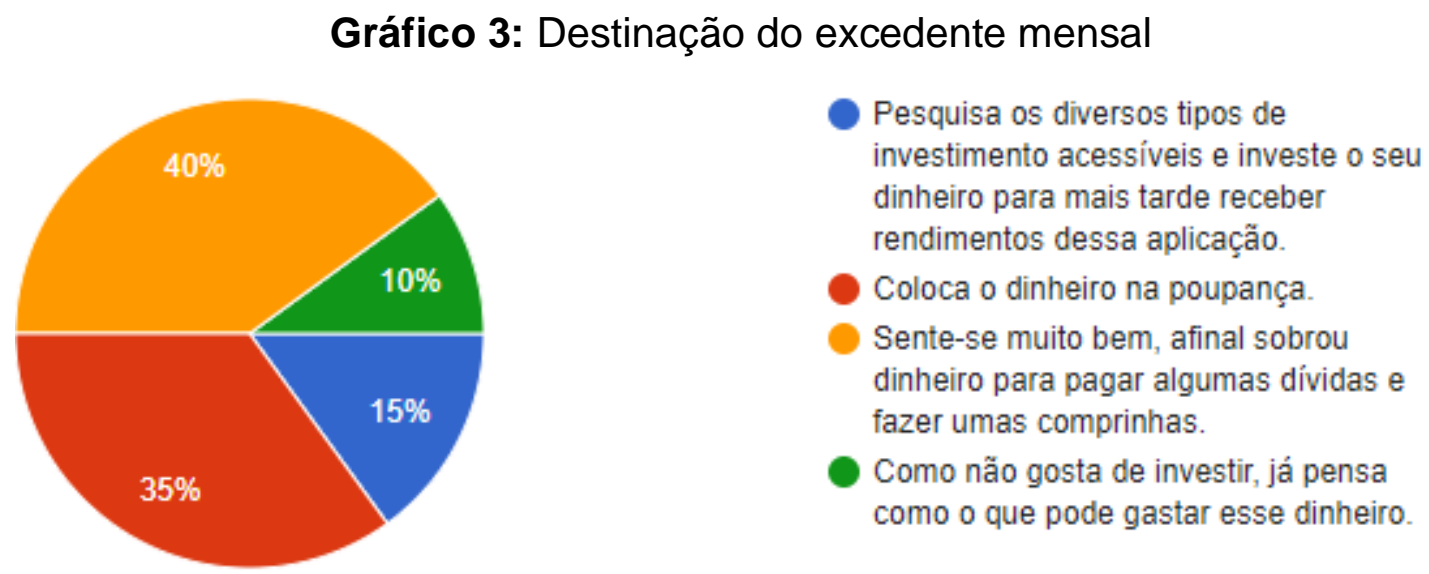

Fonte: Elaborado pela autora

Por meio de apreciação do Gráfico 3, pode-se inferir que, para metade dos entrevistados, o excedente do mês é destinado à consumação. Nesse sentido, a Educação Financeira pode ajudar, segundo Bacen (2013), na compreensão de que o ato de poupar e investir são um bom caminho, tanto para concretizar sonhos, realizando projetos, como para reduzir os riscos em eventos inesperados; e, por fim, manter uma boa gestão financeira pessoal.

Em relação à aposentadoria, $85 \%$ dos estudantes não fizeram um planejamento para essa etapa da vida. Como bem destacou Domingos (2016), a minoria dos aposentados conseguem se manter financeiramente, o restante precisa continuar trabalhando ou depende da ajuda de familiares e/ou terceiros. Nesse sentido, a Educação Financeira dá a devida importância ao planejamento de longo prazo, garantindo uma aposentadoria sustentável.

Após a investigação do perfil e dos hábitos financeiros dos estudantes, pôdese inferir que a introdução de conteúdos básicos sobre finanças pessoais era bemvinda aos estudantes, tendo em vista a promoção da reflexão sobre a relação com dinheiro e sobre suas ações, inclusive pode ser tornar uma ferramenta para 0 desenvolvimento da consciência sobre seu papel na sociedade. Sendo assim, a aplicação do produto educacional, no formato de aula expositiva e com utilização de exemplos práticos do cotidiano, ocorreu no mês de dezembro de 2019, e foi realizada pelo professor responsável pela disciplina de Comportamento Humano nas Organizações.

A segunda etapa da coleta de dados ocorreu logo após a aplicação do produto educacional e buscou avaliar o impacto do conteúdo transmitido aos estudantes, tendo em vista sua contribuição para a formação integral, e consequentemente, o fortalecimento da cidadania e, ainda, investigar, para sugestão de pesquisas futuras, os conteúdos de Educação Financeira que os estudantes desejam aperfeiçoamento. A amostra nessa segunda etapa foi menor, tendo em vista a ausência de três estudantes na aula da disciplina. Portanto, 17 alunos receberam a introdução de conteúdos de finanças pessoais por meio da aplicação da cartilha pelo professor. 
Os discentes em sua totalidade consideraram importante a inclusão da Educação Financeira na EPT. Em relação à aplicação, 70,6\% da amostra considerou o conteúdo de fácil compreensão e para 94,1\% dos estudantes o tempo de duração da aplicação foi adequado. Em relação aos conceitos estudados durante a aplicação da primeira edição da cartilha "Educação Financeira na Educação Profissional e Tecnológica", $70,6 \%$ dos estudantes manifestaram assumir novas atitudes financeiras, passando, inclusive, a colaborar no contexto familiar, incentivando outras pessoas a adotarem comportamentos financeiros mais saudáveis. Ou seja, a proposta de introdução ao tema, além de facilitar a compreensão dos conceitos, também fornece informações e condições para que os estudantes transformem os conhecimentos em comportamentos saudáveis.

Todos os estudantes declararam que o conteúdo disponibilizado contribuiu para uma reflexão a respeito do consumo consciente do dinheiro e do crédito e para o desenvolvimento da sua capacidade de pensar criticamente, refletindo sobre soluções para problemas da sociedade, e ainda será útil para sua atuação profissional e participação na sociedade. Dos 17 estudantes, 16 afirmaram que o conteúdo apresentou situações relevantes do dia a dia e que contribuiu para o fortalecimento da cidadania.

No Gráfico 4, é possível verificar os temas em que os estudantes demonstraram interesse em obter mais informações.

Gráfico 4: Temas de interesse dos estudantes

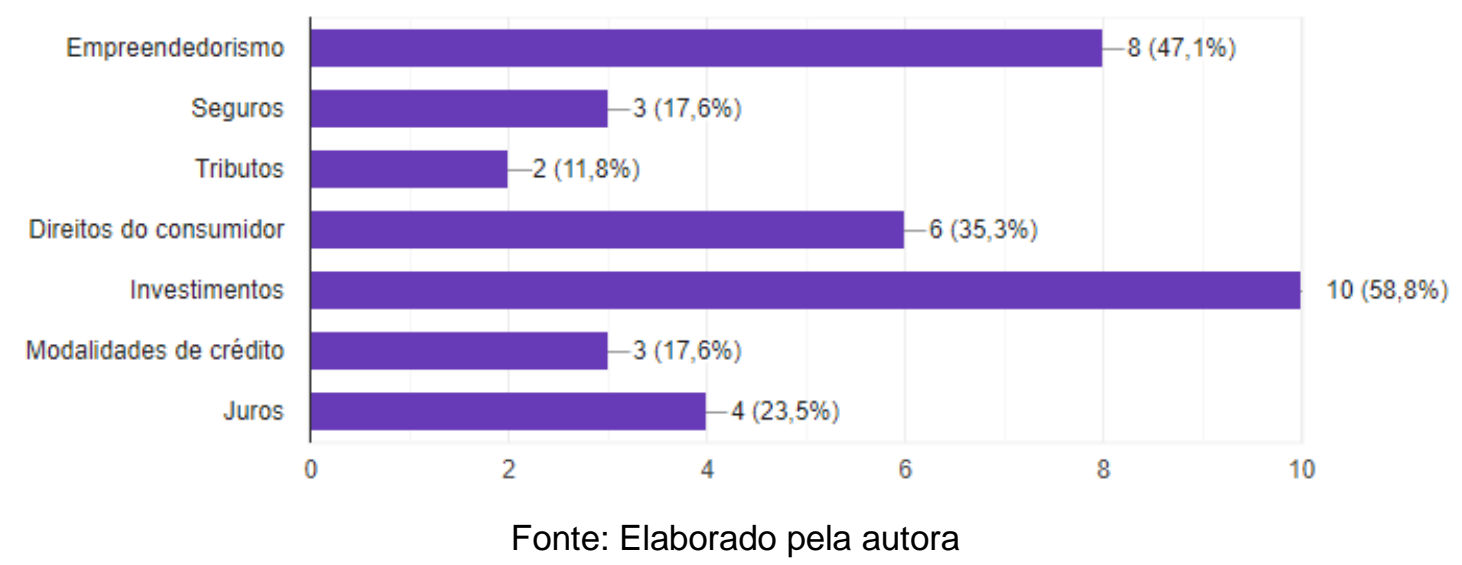

Conforme apresentação do Gráfico 4, pode-se ratificar que os alunos possuem mais interesse em obter informações nos temas investimentos, empreendedorismo e direitos do consumidor. Finalmente, $94,1 \%$ (noventa e quatro vírgula um por cento), recomendariam a 1를 Edição da cartilha para algum amigo.

A terceira e última etapa de aplicação dos questionários foi destinada ao professor que realizou a aplicação do produto educacional proposto. Sobre o tema, o professor considerou importante a inclusão da Educação Financeira na EPT e afirmou que os alunos demonstraram interesse no tema, inclusive em aprofundar os estudos. 
Considerando que se tratou de conteúdo básico e introdutório de finanças pessoais, o tempo de duração da aplicação de uma aula mostra-se adequado. Em relação ao conteúdo da primeria edição da cartilha "Educação Financeira na Educação Profissional e Tecnológica", foi considerado pelo professor de fácil compreensão, contribuiu para uma reflexão a respeito do consumo consciente do dinheiro e do crédito, apresentou situações relevantes do dia a dia, se mostrou útil para os estudantes no que se refere à sua atuação profissional e participação na sociedade e, ainda, que contribuiu para o fortalecimento da cidadania. Por fim, o professor afirmou que recomendaria a primeira edição da cartilha para algum amigo e/ou professor, e o tema que considerou de grande valia para a formação integral dos estudantes foi investimentos, o que vai ao encontro do tema em que os estudantes demonstraram mais interesse em obter informações.

\section{CONSIDERAÇÕES FINAIS}

Tendo em vista a importância da disseminação do ensino de Educação Financeira à população, inclusive prevista na ENEF, levar discentes e docentes a refletir coletivamente a respeito de situações financeiras do cotidiano pessoal e familiar contribui para o desenvolvimento da consciência sobre seu papel na sociedade, de forma que possibilite uma reflexão sobre suas ações, percebendo como são influenciadas na sua vida e na sociedade como um todo. A realidade socioeconômica brasileira exige, para Moura (2013), do ponto de vista teórico e éticopolítico, conceber e materializar um tipo de ensino que garanta uma base unitária para todos, fundamentado na concepção de formação humana integral, omnilateral ou politécnica, tendo com eixo estruturante o trabalho, a ciência, a tecnologia e a cultura. Nesse sentido, a Educação Financeira, entendida como tema transversal, dialoga com as diversas disciplinas dos currículos, de forma a possibilitar ao estudante compreender como concretizar suas aspirações e estar preparado para as diversas fases da vida.

Inserir essa temática na educação formal, sobretudo na EPT, pode ser uma maneira eficiente de contribuir na construção da autonomia dos estudantes, visando sempre sua emancipação. Afinal, como afirma Perissé (2014), o modo de interpretação do dinheiro, elemento-chave da atual sociedade, se tornou essencial para a formação integral e humanizadora dos estudantes. Por isso, a necessidade de oportunizar aos estudantes da EPT experiências pouco exploradas no currículo, mas que podem contribuir para sua formação integral. Ainda corroborando com 0 entendimento, segundo Moura (2013), é possível, e necessário, plantar e cuidar para que cresçam as sementes da formação humana integral, aproveitando-se das contradições do sistema de capital.

Inserindo a Educação Financeira nas escolas, consegue-se atingir, de uma só vez, estudantes, professores e, de forma indireta, familiares e comunidade em geral. Ratificando esse entendimento, os estudantes afirmaram que, para muitos, apesar de ter sido a primeira vez que tiveram contato com a Educação Financeira, ela foi importante para assumir novas atitudes financeiras, passando, inclusive, a colaborar no contexto familiar, incentivando outras pessoas a adotarem comportamentos financeiros mais saudáveis. Ou seja, a proposta de introdução ao tema, além de 
facilitar a compreensão dos conceitos, também fornece informações e condições para que os estudantes transformem os conhecimentos em comportamentos saudáveis.

Vale ressaltar que o professor e a totalidade dos estudantes consideraram importante a inclusão da Educação Financeira na escola. Além disso, segundo o professor, os alunos demonstraram interesse no tema, inclusive em aprofundar os estudos. Ademais, a análise dos dados mostra que a pesquisa alcançou seu objetivo, que foi registrar a percepção dos estudantes e dos professores sobre a introdução da Educação Financeira na EPT, por meio de uma cartilha, e pode-se inferir que a introdução de conteúdos básicos sobre finanças pessoais é bem vista por estudantes e professores, tendo em vista a promoção da reflexão a respeito do consumo consciente do dinheiro e do crédito, inclusive pode se tornar uma ferramenta para aperfeiçoamento da sua atuação profissional. Pode-se inferir, ainda, que projetos como esse, que visam introduzir temáticas pouco exploradas nos currículos escolares, contribui para o fortalecimento da cidadania.

Por fim, esse estudo pode contribuir para futuras pesquisas. A saber, predominantemente, os estudantes demonstraram interesse em obter mais conhecimentos na área de investimentos, inclusive, esse assunto foi considerado, na visão do professor, de grande valia para a contribuição na formação integral dos discentes. Ademais, pesquisas como essa podem ser realizadas em outros contextos da educação formal, como por exemplo, no ensino fundamental ou superior.

Como continuidade desta pesquisa foi desenvolvido 0 site edufinanceiraept.com no qual os alunos desta turma terão acesso ao conteúdo da cartilha e poderão responder se neste novo formato o conteúdo apresenta-se de algum modo a complementar a experiência com o professor. Estes dados serão compilados e analisados em publicações futuras.

\section{REFERÊNCIAS}

AEF-BRASIL. EaD - Educação Financeira nas Escolas. 01 mai 2019 a 07 jun. 2019. Notas de Aula. Disponível em: http://www.vidaedinheiro.gov.br/moodle/.

BACEN, Banco Central do Brasil. Caderno de Educação Financeira: Gestão de Finanças Pessoais. Brasília: 2013. Disponível em:

https://www.bcb.gov.br/pre/pef/port/caderno_cidadania_financeira.pdf. Acesso em: 15 mar. 2019.

BRASIL. CONEF. Educação Financeira nas Escolas. Ensino Médio. Brasília, 2013. Disponível em: http://www.vidaedinheiro.gov.br/livros-ensino-medio/. Acesso em: 20 nov 2019.

BRASIL. Decreto no 7.397, de 22 de dezembro de 2010. Institui a ENEF, dispõe sobre sua gestão e dá outras providencias. Disponível em:

http://www.planalto.gov.br/ccivil_03/_Ato2007-2010/2010/Decreto/D7397.htm.

Acesso em: 24 out. 2018. 
BRASIL. Enef. Orientação para Educação Financeira nas Escolas. Disponível em: http://www.vidaedinheiro.gov.br/wp-content/uploads/2017/08/DOCUMENTOENEF-Orientacoes-para-Educ-Financeira-nas-Escolas.pdf. Acesso em: 23 out. 2018.

BRASIL. Nova Base Nacional Comum Curricular: avanço na Educação Brasileira. Disponível em: http://www.vidaedinheiro.gov.br/bncc-educacao-

brasileira/?doing_wp_cron=1541030788.7945261001586914062500. Acesso: 31 out. 2018.

BRASIL. Programas Transversais. Disponível em:

http://www.vidaedinheiro.gov.br/programas-transversais/. Acesso em: 24 out. 2018.

BRASIL. Quem Somos. Disponível em:

http://www.vidaedinheiro.gov.br/quemsomos/. Acesso em: 28 out. 2018.

BRASIL. Ministério da Educação. Organização para a Cooperação e

Desenvolvimento Econômico - OCDE. Disponível em:

http://portal.mec.gov.br/busca-geral/480-gabinete-do-ministro-

1578890832/assessoria-internacional-1377578466/20746-organizacao-para-acooperacao-e-desenvolvimento-economico-ocde. Acesso em: 06 nov. 2018.

CNC. Pesquisa Endividamento e Inadimplência do Consumidor: Dez/2019.

Disponível em:

file:///C:/Users/Marina/Downloads/http_cnc.org.br_sites_default_files_2020-

01_An\%25C3\%25A1lise_Peic_dezembro_\%25202019.pdf. Acesso em: 29 jan. $20 \overline{2} 0$.

DOMINGOS, R. A importância da educação financeira nas escolas: nova visão para uma nova sociedade. TV Cidade 10, 2016. Disponível em:

https://www.tvcidade10.com.br/index.php/2016-04-01-14-03-

46/variedades/item/1707-a-importancia-da-educacao-financeira-nas-escolas-novavisao-para-uma-nova-sociedade. Acesso em: 06 fev. 2020.

FERREIRA, Adenilson Bento. Educação Financeira - Desenvolvendo a Cidadania. Disponível em: www.diaadiaeducacao.pr.gov.br/portals/pde/arquivos/1582-8.pdf. Acesso em 28 out. 2018.

FONSECA, S. M.; NETO, J. A. M. Metodologias ativas aplicadas à educação a distância: revisão de literatura. Revista EDaPECI,v.17. n. 2, p. 185-197, mai./ago. 2017.

HILL, N. Quem pensa enriquece. São Paulo: Fundamento Educacional, 2009. KÁPLUN, G. (2003). Materiais educativos: experiência de aprendizado. Revista Comunicação \& Educação, 271, 46-60.

KERN, D. T. B. Uma reflexão sobre a importância de inclusão de educação financeira na escola pública. 2009. Dissertação (Mestrado em Ensino de Ciências Exatas) - UNIVATES, Lajeado, 2009.

LEITE, P. S. C. (2018). Produtos Educacionais em Mestrados Profissionais na Área de Ensino: uma proposta de avaliação coletiva de materiais educativos. Atas CIAIQ 2018 - Investigação qualitativa em educação, 1, 330-339.

MOURA, D. H. Ensino médio integrado: subsunção aos interesses do capital ou travessia para a formação humana integral?. Educ. Pesqui. São Paulo, v. 39, n. 3, 
p. 705-720, jul/set. 2013. Disponível em: https://www.scielo.br/pdf/ep/v39n3/10.pdf. Acesso em 12 mai. 2020.

PERISSÉ, Gabriel. Formação integral: educação financeira como tema transversal. São Paulo: Editora DSOP, 2014.

STEPHANI, M. Educação Financeira: uma perspectiva interdisciplinar na construção da autonomia do aluno. 2005. Dissertação (Mestrado em Educação em Ciências e Matemática) - PUC, Rio Grande do Sul, 2005. 